\title{
ÉLODIE RIPOLL, Penser la couleur en littérature. Explorations romanesques des Lumières au réalisme
}

\section{Vittorio Fortunati}

\section{(2) OpenEdition}

\section{Journals}

\section{Edizione digitale}

URL: https://journals.openedition.org/studifrancesi/31733

DOI: 10.4000/studifrancesi.31733

ISSN: 2421-5856

\section{Editore}

Rosenberg \& Sellier

\section{Edizione cartacea}

Data di pubblicazione: 1 août 2020

Paginazione: $402-403$

ISSN: 0039-2944

\section{Notizia bibliografica digitale}

Vittorio Fortunati, «ÉLOdie RIPolL, Penser la couleur en littérature. Explorations romanesques des Lumières au réalisme», Studi Francesi [Online], 191 (LXIV | II) | 2020, online dal 01 septembre 2020, consultato il 18 septembre 2021. URL: http://journals.openedition.org/studifrancesi/31733 ; DOI: https://doi.org/ 10.4000/studifrancesi.31733

Questo documento è stato generato automaticamente il 18 septembre 2021.

\section{(c) (i) (9)}

Studi Francesi è distribuita con Licenza Creative Commons Attribuzione - Non commerciale - Non opere derivate 4.0 Internazionale. 


\title{
ÉLODIE RIPOLL, Penser la couleur en littérature. Explorations romanesques des Lumières au réalisme
}

\author{
Vittorio Fortunati
}

\section{NOTIZIA}

ÉLODIE RIPOLL, Penser la couleur en littérature. Explorations romanesques des Lumières au réalisme, Paris, Classiques Garnier, 2018, 492 pp.

1 Nell'ambito delle arti decorative e applicate (abiti, accessori, mobili e soprammobili...), nel XVIII secolo si assiste, se così si può dire, a un "trionfo dei colori", soprattutto di quelli chiari. Sotto questo aspetto, il Settecento si distingue dai due secoli tra i quali esso si colloca, caratterizzati entrambi (in particolare l'ottocento) dal gusto dominante per le tonalità scure, se non addirittura per il nero. Può quindi destare qualche stupore il fatto che nel secolo dei Lumi i colori siano menzionati piuttosto di rado nelle opere letterarie (sia narrative, sia poetiche), mentre a partire dal periodo romantico si constata una frequenza decisamente più alta. È certamente legittimo mettere il fenomeno in relazione con la presenza di numerose descrizioni nei romanzi (ma anche in molti testi poetici) del xIX secolo. Sarebbe, tuttavia, riduttivo e semplicistico vedere la ragione principale della maggiore presenza dei colori in una mera questione di tecnica narrativa. In realtà, una certa sensibilità degli scrittori per gli aspetti cromatici si manifestò già durante la seconda metà del XVIII secolo e si accentuò nella porzione finale di esso, in quel periodo che si definisce ormai correntemente tournant des Lumières. In una fase storica in cui la cultura umanistica e la scienza mantenevano ancora stretti legami, apparvero diversi saggi di ottica, nei quali lo studio dei colori aveva un ruolo importante e che non destarono interesse solo in ambito prettamente scientifico: tra gli autori più noti, infatti, va senz'altro citato un poeta come Johann Wolfgang Goethe. Parallelamente, si manifestò una nuova attenzione dei letterati verso 
la pittura, che si concretizzò nella nascita e nella diffusione della critica d'arte (pensiamo, naturalmente, ai Salons di Denis Diderot). Successivamente, il Romanticismo portò a un avvicinamento tra scrittori e artisti, due categorie che in precedenza non tendevano molto a mischiarsi.

2 Le cause per le quali gli autori ottocenteschi menzionano spesso i colori, ora nelle descrizioni di persone, oggetti, ambienti, ora all'interno delle figure retoriche sono diverse, insomma, e di diversa portata. Di questa complessità rende conto molto bene il volume di É. Ripoll, il quale prende in esame un corpus di una cinquantina di romanzi in lingua francese, che vanno grosso modo dalla Manon Lescaut dell'abbé Prévost fino alla Chartreuse de Parme di Stendhal, a cui si aggiungono numerose opere letterarie e saggistiche dello stesso periodo, con il sostegno di una vasta bibliografia critica (pp. 454-476). Nella sua analisi l'autrice smonta diversi luoghi comuni e sottolinea, fra l'altro, due aspetti interessanti: da un lato, che le valenze simboliche dei colori non sono costanti, ma variano a seconda del tempo e del contesto; dall'altro, che la presenza (così come l'assenza) di riferimenti cromatici non è mai neutra, essendo sempre legata a un sistema di valori e ad una visione particolare della realtà. In sintesi, questo saggio ha il merito di affrontare una tematica ancora poco esplorata e di suggerire utili riflessioni di carattere più generale. 